Research Article

\title{
The Exposure of Pharmacists and Pharmacy Assistants to COVID-19: A Cross-sectional Study in Libya
}

Faisa Alzunni, Seham Shaboun

University of Benghazi, Benghazi, Libya.

DOI: https://doi.org/10.24321/2455.7048.202108

I $\quad \mathbf{N} \quad \mathbf{F} \quad \mathbf{O}$

\section{Corresponding Author:}

Faisa Alzunni, University of Benghazi, Benghazi, Libya.

E-mail Id:

faisa.alzunni@uob.edu.ly

Orcid Id:

https://orcid.org/0000-0002-3598-3065

How to cite this article:

Alzunni F, Shaboun S. The Exposure of Pharmacists and Pharmacy Assistants to COVID-19: A Crosssectional Study in Libya. Epidem Int. 2021;6(3):919.

Date of Submission: 2021-07-21

Date of Acceptance: 2021-08-26

\author{
$\begin{array}{llllllll}\mathbf{A} & \mathbf{B} & \mathbf{S} & \mathbf{T} & \mathbf{R} & \mathbf{A} & \mathbf{C} & \mathbf{T}\end{array}$
}

Introduction: As per the WHO reports dated July 7, 2021, 184,324,026 confirmed cases of COVID-19 were found in the world and 196,894 cases were found in Libya. Healthcare workers (HCWs), pharmacists, in particular, have been affected a lot because of COVID-19. Community pharmacies are considered workplaces with elevated exposure risk to COVID-19.

Method: This study aims to roughly estimate the risk of COVID-19 exposure among pharmacists and pharmacy assistants working in pharmacies in Libya. An anonymous cross-sectional online survey was conducted among pharmacists and pharmacy assistants working in hospital pharmacies and community pharmacies. Between November 11th, 2020 and January 7th, 2021, a Google Form questionnaire was delivered through social media and instant messaging platforms, to certified community pharmacists and pharmacy assistants residing in Libya.

Results: Out of 207 respondents, the majority (72.4\%) reported having at least one or more flu-like symptoms. In addition, $52.17 \%$ of them reported that one of their relatives had at least one or more flu-like symptoms. The most common symptoms reported by respondents were headache (46.9\%), tiredness (42.5\%), fever (31.9\%), and loss of smell and taste sensation (29.0\%). The period with the highest number of all the symptomatic respondents as well as those with symptoms suggestive of COVID-19 was between August to October 2020. Correspondingly, 108 (52.17\%) symptomatic respondents had a relative with symptoms.

Conclusion: The majority of respondents reported having flu-like symptoms in the period from August to October. Moreover, the highest cumulative number of people with suggestive COVID-19 symptoms reported their symptoms in the same period.

Keywords: COVID-19, Pharmacists and Pharmacy Assistants, Exposure to COVID-19 


\section{Introduction}

COVID-19 is an epidemic caused by the coronavirus (SARSCoV-2), which is an enveloped RNA virus, diversely found in humans and wildlife. Under a microscope, the virus has a typical crown-like appearance because of the presence of glycoprotein spikes on its envelope. ${ }^{1}$ The respiratory tract of mammals, including humans, is the main targeted organ by coronaviruses. The coronaviruses (CoV) are associated with common cold, pneumonia, and severe acute respiratory syndrome (SARS). ${ }^{2}$

On December 31, 2019, a number of patients were reported suffering from acute respiratory illness; all of them were in contact with the Hunan seafood in the city of Wuhan in China. On January 7, 2020, it was confirmed that a novel coronavirus (2019-nCoV) was associated with these cases. ${ }^{5}$ As of February 4, 2020, the National Health Commission of China reported that the confirmed cases had increased to 20,471 . Among them, 2,788 were reported with severe illness, and there were 425 deaths. On January 30, 2020, the World Health Organization (WHO) stated that the 2019nCoV outbreak constitutes a Public Health Emergency of International Concern. ${ }^{2,6}$

On February 11, 2020, the World Health Organization (WHO) put an official name for the pandemic caused by coronavirus (SARS-CoV-2), which is COVID-19, short for "coronavirus disease 2019,"

The disease may appear as a mild asymptomatic infection, which can progress to severe respiratory failure. The main symptoms of the virus are fever, dry cough, muscle ache, fatigue, and shortness of breath while the less common symptoms include sore throat, dizziness, headache, runny nose, diarrhoea, and nausea/ vomiting. ${ }^{2,7-10}$ COVID-19 complications that may result in death include pneumonia (need ventilator), acute respiratory distress syndrome, and septic shock. ${ }^{11}$

According to the WHO reports dated July 7, 2021, there were 184,324,026 confirmed cases globally and 3,992,680 deaths in 223 countries around the world. ${ }^{14}$ On the national level, according to Bredan \& Bakoush (2021), ${ }^{12}$ a case of COVID-19 was first recognised in Tripoli, Libya on March 24, 2020, as the case was coming back from Saudi Arabia and then it was confirmed. The second COVID-19 case was confirmed on April 7, 2020, in Benghazi, Libya. The suspicious patient was a 53-year-old male recently who had returned from Turkey through Tunisia. ${ }^{13}$ Two months later, the number of reported COVID-19 cases started to increase. However, the situation became an epidemic in the southern region of the country (Sabha) and then spread to the western and eastern parts. ${ }^{12}$ According to the "WHO Coronavirus (COVID-19) Dashboard", till July 7,2021 , there were 196,894 total confirmed cases, and
3,215 coronavirus-related deaths reported in Libya since the pandemic began. ${ }^{14}$

During the coronavirus outbreak, healthcare workers (HCWs) have been one of the most affected groups and the exposure of health care workers to COVID-19 can be determined by the probability of coming into direct contact with infected patients or with contaminated surfaces, through aerosol-generating procedures on patients with COVID-19 without using adequate personal protection. ${ }^{15}$

Community pharmacies have been considered as primary health services with elevated exposure risk to COVID-19. These workplaces and environments require frequent or close contact with people (less than 2 meters) who may be carriers of COVID-19 or suspected COVID-19 patients. ${ }^{10}$

In Libya, pharmacists are the most vital and accessible healthcare providers and serve as the first and direct contact point of patients with the healthcare system. Moreover, in rural areas, pharmacists could replace physicians since many people go directly to the pharmacists and got their treatment without being examined by a physician. This puts the pharmacists at increased risk of direct contact with people who may be infected with COVID-19. ${ }^{16}$ The number of reported infections and deaths among health care workers is high especially in Europe and according to Bandyopadhyay et al. (2020), ${ }^{17}$ for every $100 \mathrm{HCWs}$ who were infected, one died.

\section{Method}

Study Design: An anonymous cross-sectional online survey was conducted among pharmacists and pharmacy assistants working in hospital pharmacies and community pharmacies.

Sample Size: An approximate number of pharmacists and pharmacy assistants working in different health sectors in Libya (hospital pharmacies and community pharmacies) was estimated by the Libyan pharmacists association to determine the frame of sampling. A representative sample of 200-300 participants was eligible for the study.

Data Collection: Between November 11, 2020, and January 7, 2021, a Google Form questionnaire was delivered through social media and instant messaging platforms, such as Facebook and WhatsApp, to certified Libyan pharmacists residing in Libya. Certified community pharmacists who had a bachelor or diploma degree in pharmacy, were registered in the Libyan pharmacists association and worked in a pharmacy at the time of the study were included in this research. The questionnaire was made available to them from November 11, 2020, at 9:00 am to January 7, 2021, at 12:00 am.

Consent and Ethical Approval: Informed consent was obtained from all the participants before they started answering the questionnaire. The authors of this study 
obtained ethical approval from the Dean of Pharmacy at the University of Benghazi.

Study Questionnaire: The first part of the questionnaire consisted of eight questions on demographics, namely gender and age, and occupational data including educational level, professional category, working setup, job position, years of experience, and the number of co-workers. The second part of the questionnaire inquired about clinical data including comorbidities.

The third part of the questionnaire consisted of six questions. The first question examined the exposure of pharmacists to COVID-19 during the period from March 2020 until the time of closure (January 7, 2021, at 12:00 am). The respondents were asked if they had developed one or more flu-like symptoms during this period. In the second question, they were asked to select the symptoms they experienced from a list of 12 symptoms (multiple answers allowed) that were most commonly associated with COVID-19 as per the literature. In the third question, the respondents were asked to select the symptoms of their relatives, who were more than 50 years old and were living in the same household, from a similar list of 12 symptoms. In the fourth question, the respondents were asked to specify exactly the month in which they had these symptoms. The fifth question inquired whether they had tested for COVID-19 or not, and what was the result of the test (if they had tested for it). In the sixth question, respondents were asked whether their symptoms and their relatives' symptoms required hospital or intensive care unit (ICU) admission. The last part of the questionnaire inquired about the protective measures used by respondents.

\section{Statistical Analysis}

Analysis of data was done using SPSS (Statistical Package for Social Science, version 21). Descriptive statistics (frequency and percentages) were used for most variables. Multiple answer questions were analysed using multiple response analysis. The correlation or association between variables was found using Pearson's Chi-square test. For all analyses, two-sided statistical significance was defined as $p<0.05$.

\section{Results}

\section{Demographic Data of Respondents}

About 207 pharmacists and pharmacy assistants working in public and private hospitals and community pharmacies in Libya at the time of study responded to a questionnaire that investigated the exposure of pharmacists to the COVID-19 pandemic. The demographic data have been shown in Table 1. The sample was composed of 86 males $(41.5 \%)$ and 121 (58.5\%) females, and the majority $(102,49.3 \%)$ belonged to the age group of 26-35 years. Most of the respondents were pharmacists $(153,73.9 \%)$. Maximum respondents $(138,66.7 \%)$ had a bachelor degree, and the majority of respondents were working at community pharmacies (157, $75.8 \%)$. The most frequent job practised by respondents was that of a dispenser $(80.7 \%)$, and the majority $(70.6 \%)$ had an experience of less than 5 years.

Table I.Demographic Data of Respondents

\begin{tabular}{|c|c|c|}
\hline Variables & Frequencies & Percentages \\
\hline \multicolumn{3}{|l|}{ Gender } \\
\hline Male & 86 & 41.5 \\
\hline Female & 121 & 58.5 \\
\hline \multicolumn{3}{|l|}{ Age (years) } \\
\hline $18-25$ & 78 & 37.7 \\
\hline $26-35$ & 102 & 49.3 \\
\hline$\geq 36$ & 27 & 13.0 \\
\hline \multicolumn{3}{|l|}{ Working setup } \\
\hline Community pharmacy & 157 & 75.8 \\
\hline Private hospital pharmacy & 15 & 7.2 \\
\hline $\begin{array}{c}\text { General hospital } \\
\text { pharmacy }\end{array}$ & 23 & 11.1 \\
\hline Polyclinic pharmacy & 12 & 5.8 \\
\hline \multicolumn{3}{|l|}{ Professional level } \\
\hline Pharmacist & 153 & 73.9 \\
\hline Pharmacist assistant & 54 & 26.1 \\
\hline \multicolumn{3}{|l|}{ Pharmacist degree } \\
\hline Diploma & 54 & 26.1 \\
\hline BSC & 138 & 66.7 \\
\hline Masters or PhD & 15 & 7.2 \\
\hline \multicolumn{3}{|l|}{ Job position } \\
\hline Dispenser & 167 & 80.7 \\
\hline Store manager & 54 & 26.1 \\
\hline Store owner & 20 & 9.7 \\
\hline \multicolumn{3}{|l|}{ Year of service } \\
\hline$<1$ & 68 & 32.9 \\
\hline $1-5$ & 78 & 37.7 \\
\hline $6-15$ & 51 & 24.6 \\
\hline$>15$ & 10 & 4.8 \\
\hline \multicolumn{3}{|l|}{ Number of co-workers } \\
\hline 1 & 79 & 38.2 \\
\hline 2 & 51 & 24.6 \\
\hline 3 & 26 & 12.6 \\
\hline$>3$ & 51 & 24.6 \\
\hline \multicolumn{3}{|l|}{ Work place (city) } \\
\hline East & 124 & 59.9 \\
\hline West & 83 & 40.1 \\
\hline
\end{tabular}




\section{Frequency of Symptomatic Respondents}

Pharmacists and pharmacy assistants were asked if, during the period between March 2020 and the time of responding to the questionnaire, they had developed one or more flu-like symptoms such as fever, headache, tiredness, sore throat, dry and chesty cough, shortness of breath, loss of smell and taste, nausea, vomiting and diarrhoea, muscle pain, runny nose, and skin rash. These symptoms were considered as highly suggestive symptoms of COVID-19, according to the epidemiological data and literature..$^{2,7-10}$ The result showed that out of 207 respondents, the majority $(150,72.4 \%)$ reported having at least one or more of the aforementioned symptoms, and the number of symptoms chosen ranged from 1-11 for an individual. In addition, 108 $(52.17 \%)$ among them reported that one of their relatives had at least one or more of the aforementioned symptoms, and they ranged from 1-11 for an individual.
COVID-19 was calculated by including only those with a minimum of 3-4 most frequent symptoms of COVID-19 as reported in the epidemiological data and excluding those with symptoms that are less likely related to COVID-19.

As shown in Figure 3, the period with the highest number of respondents with all the symptoms as well as those with symptoms suggestive of COVID-19 was between August to October.

The peak was reached specifically in August. Comparably, the period with the highest number of symptomatic relatives with symptoms suggestive of COVID-19 was between August and October. Correspondingly, 108 (52.17\%) symptomatic pharmacists had a relative with symptoms.

The results of the Chi-square correlation test demonstrated that there was a significant statistical correlation between

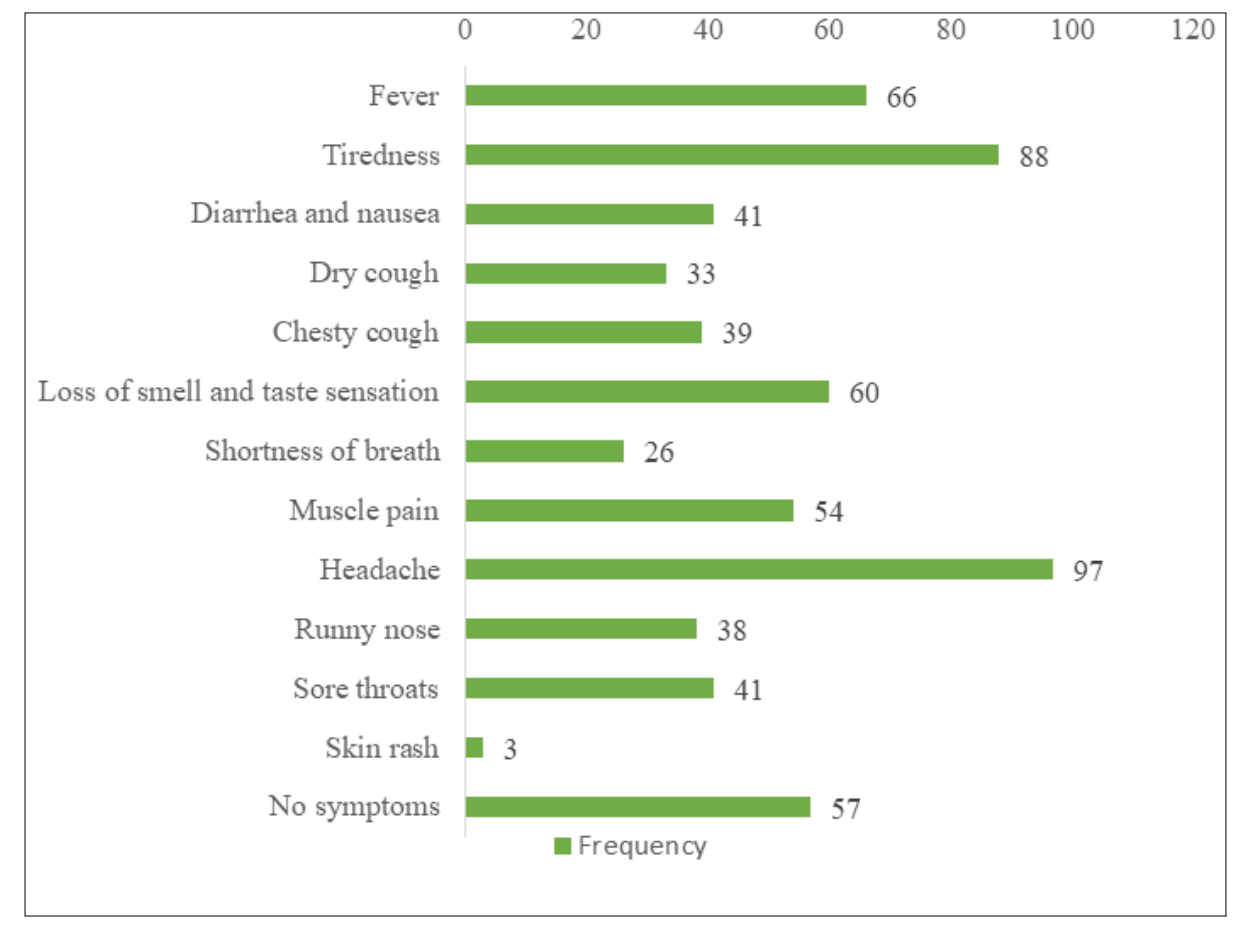

Figure I.Frequency of Symptoms in Respondents

\section{Frequency of Symptoms among Respondents and Their Relatives}

As shown in Figure 1, headache (46.9\%), tiredness (42.5\%), fever (31.9\%), and loss of smell and taste sensation (29\%) were the most common symptoms reported by the respondents, while, as shown in Figure 2, fever (41.1\%), tiredness (36.2\%), loss of smell and taste sensation (34.8\%), and headache (33.8\%) were the most common symptoms of the relatives as reported by the respondents.

\section{Period with High Cumulative Numbers of Symptomatic Respondents and Relatives}

The number of respondents with symptoms suggestive of the symptomatic status of respondents and the symptomatic status of their relatives ( $p<0.001$ ) (Figure 4). However, among the respondents who were tested for COVID-19, only eight respondents out of thirty-five tested positive for COVID-19. Those who tested positive reported having symptoms in August and September (Figure 5).

In addition, $53.47 \%$ of the symptomatic respondents reported that their symptoms lasted less than 7 days, and only $12.5 \%$ reported that their symptoms lasted more than 15 days.

The majority of respondents $(53.57 \%)$ reported that the symptoms of their relatives lasted from 7-14 days. 


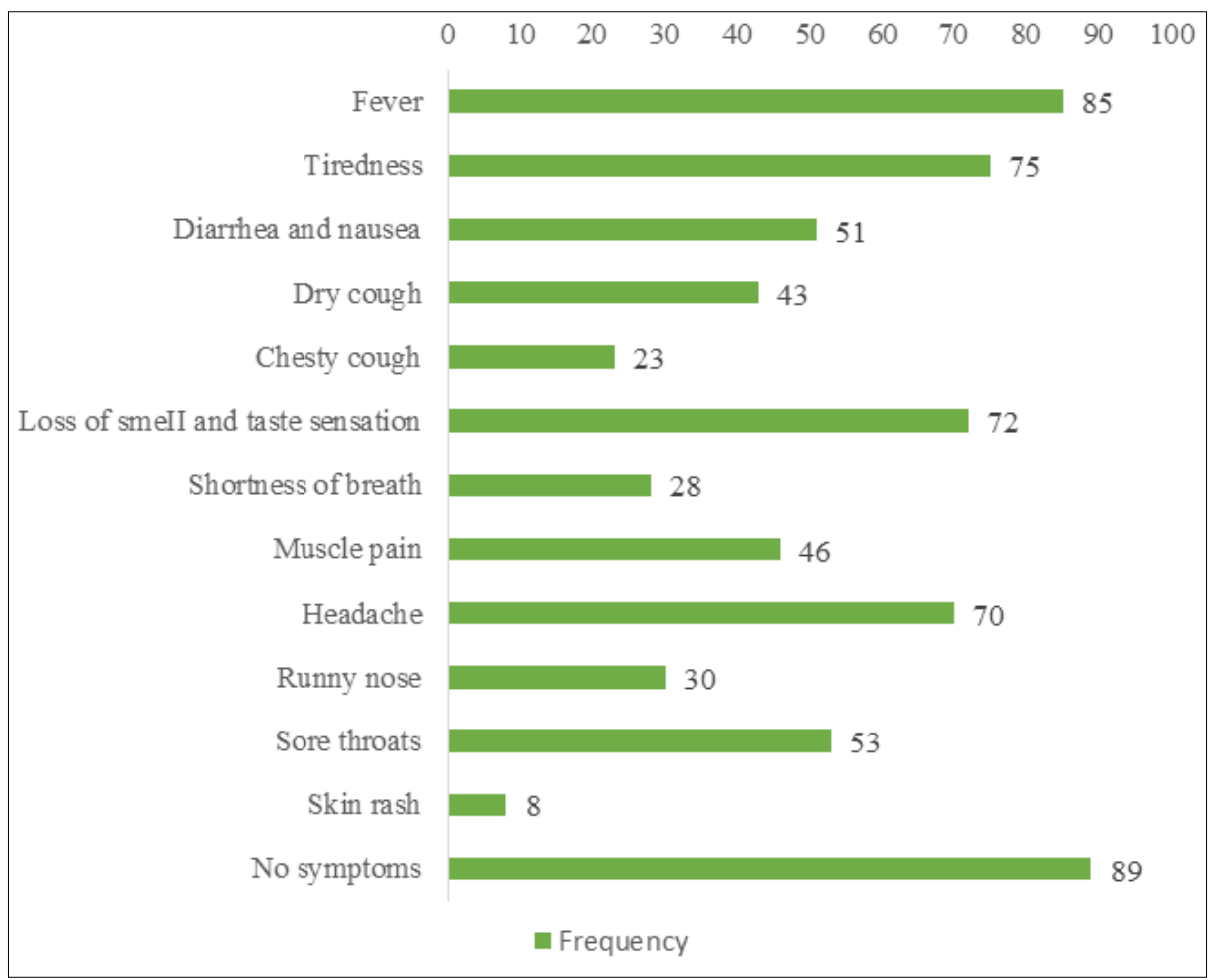

Figure 2.Frequency of Symptoms in Respondents' Relatives

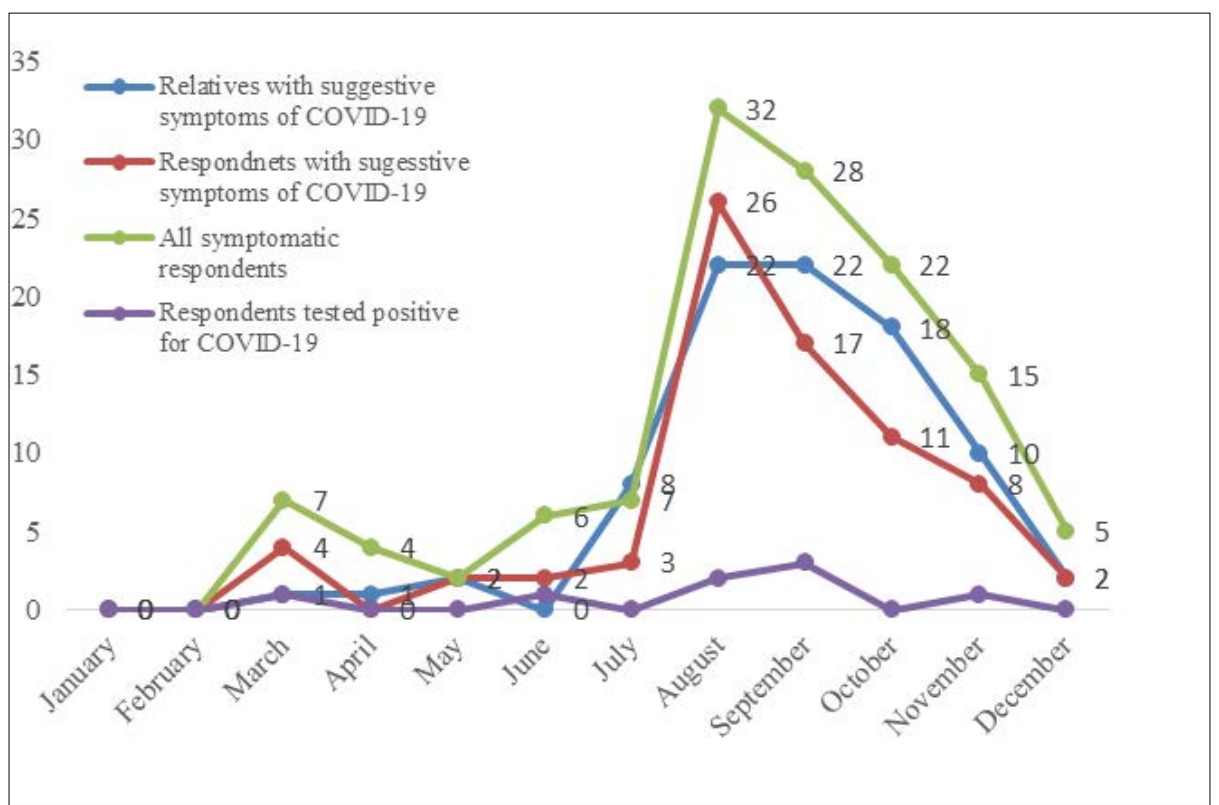

Figure 3.Month-wise Distribution of Cumulative Number of Respondents and Relatives (With Symptoms suggestive of COVID-19) in Comparison to Cumulative Number of Respondents who Tested Positive for COVID-19

\section{Comorbidities among Respondents and Relatives}

Among respondents who answered the survey, 133 (88.7\%) reported having no comorbidities, 14 (6.8\%) had one comorbidity, and the rest had two or more comorbidities. Respiratory diseases and high blood pressure (4\% each) were among the highest reported comorbidities the respondents had. In addition, as reported by respondents, $57(48.3 \%)$ relatives had no comorbidity, 32 (27.1\%) had one comorbidity, and 29 (24.5\%) had multiple comorbidities. Diabetes (28\%) and hypertension (26.3\%) were among the most common comorbidities the relatives had. 


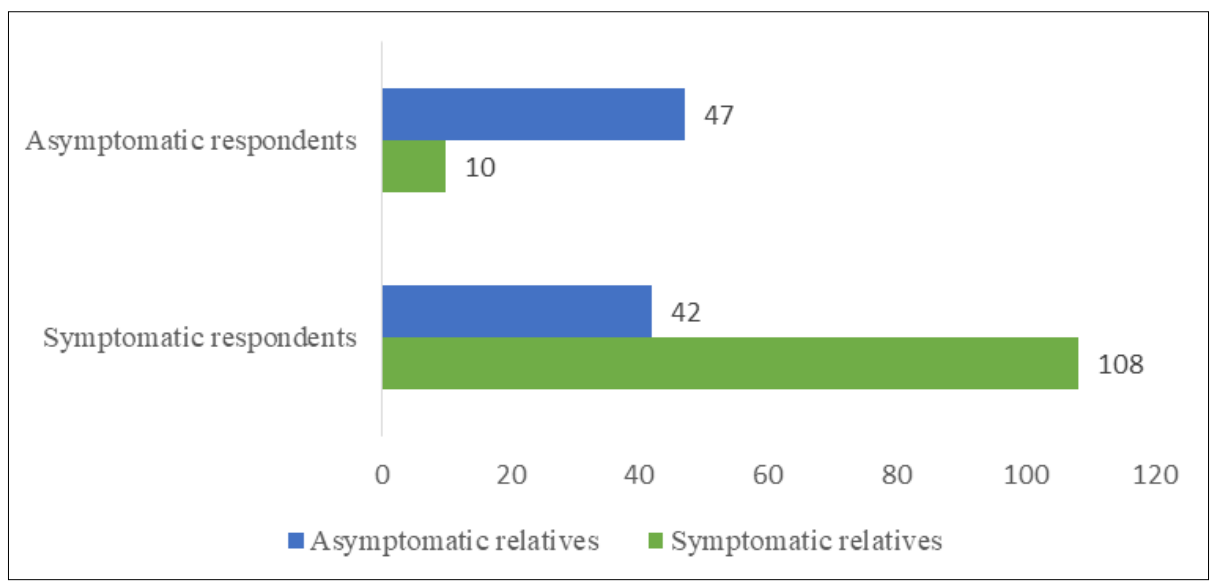

Figure 4.Correlation of the Symptomatic Status of Respondents with the Relatives

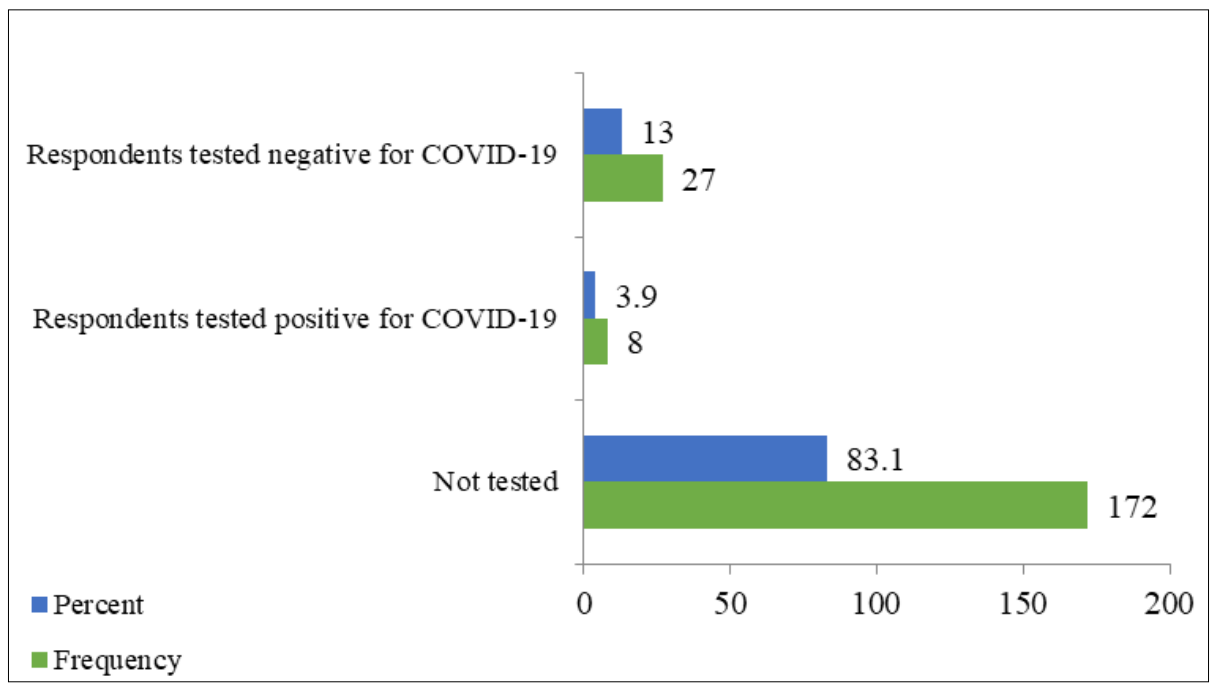

Figure 5.Frequency and Percentage of Respondents who Tested Positive/ Negative for COVID-19 and who did not take the Test

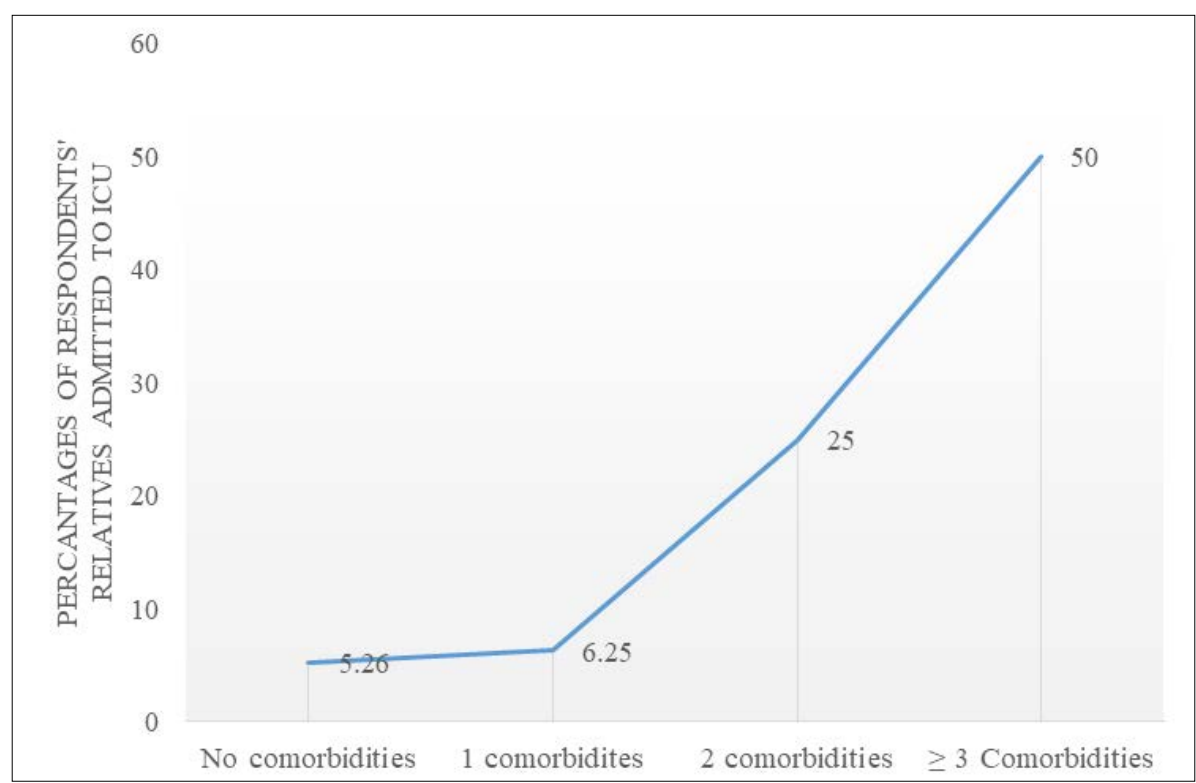

Figure 6.Association of the Number of Comorbidities in Relatives with ICU Admission 


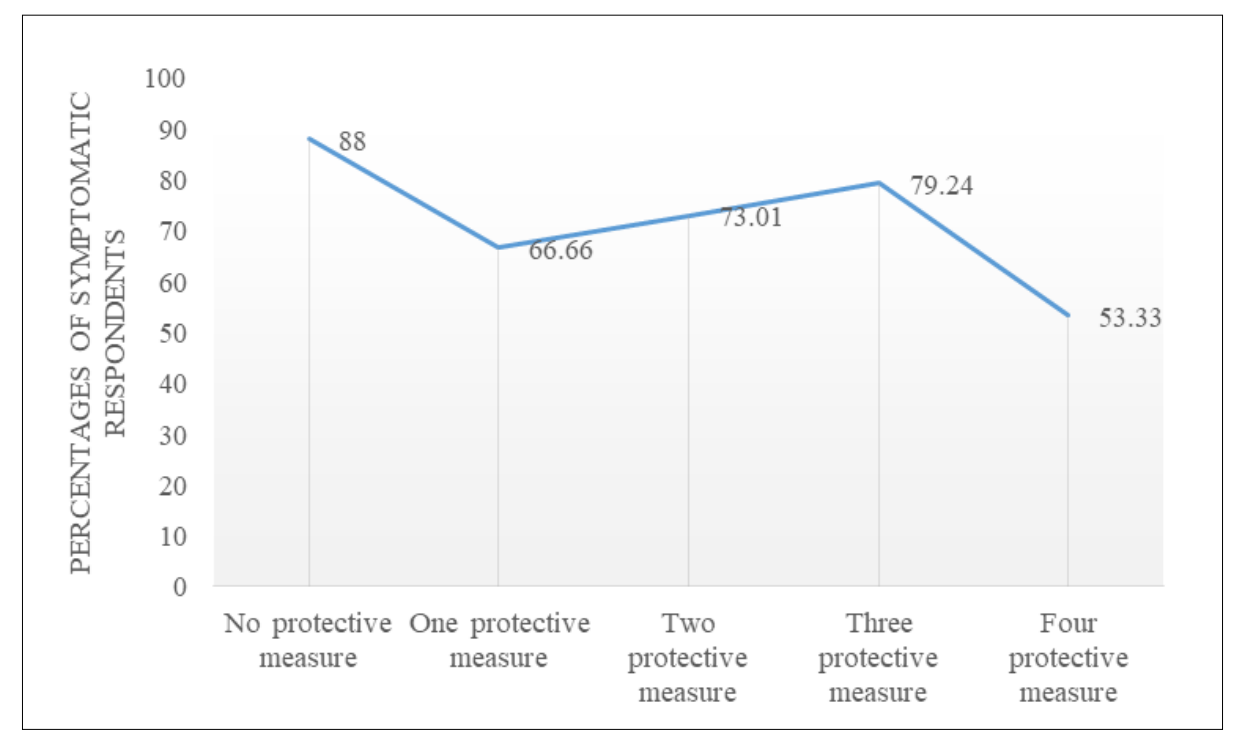

Figure 7.Association between Percentage of Symptomatic Respondents and Number of Preventive Measures used by Them

\section{Correlation between Comorbidities of Symptomatic Relatives and ICU Admission}

The pharmacists and pharmacy assistants were asked whether their relatives required admission to the intensive care unit (ICU). The result showed that there was a significant association between the comorbidities in respondents' relatives and their ICU admission as those with diabetes, immunodeficiency and respiratory disease were more likely to be admitted to ICU ( $p=0.007,<0.001$ and $<0.002$ respectively). In addition, the number of comorbidities was significantly associated with ICU admission as a high number of symptomatic relatives who were admitted to ICU had multiple comorbidities ( $p=0.004)$ (Figure 6).

\section{Protective Measures used by Respondents}

Wearing a mask as a personal protective device was the most frequent protective measure used by pharmacists and pharmacy assistants in their workplace (84.4\%). Only $12.2 \%$ of respondents did not use any protective measure. In addition, $30.43 \%$ of respondents used at least two protective measures, and $25.6 \%$ used three protective measures. There was a significant association between the decline of the number of symptomatic respondents and the number of protective measures used ( $p=0.035)$ (Figure 7).

\section{Association of the Number of Symptomatic Respondents with the Demographic Data}

As shown in Table 2, the majority of symptomatic respondents were male (69.76\%). $71.56 \%$ of the participants belonged to the age group of $26-35$ years, $74.25 \%$ worked as a dispenser, and $82.35 \%$ worked with two co-workers. However, there was no statistically significant association between the number of symptomatic respondents and age, gender, number of co-workers, and job position ( $p=$ $0.802,0.282,0.078$, and 0.085 respectively).
Table 2.Association of Symptomatic Status of Respondents with their Socio-demographic Variables

\begin{tabular}{|c|c|c|c|}
\hline \multicolumn{2}{|c|}{ Variables } & $\begin{array}{c}\text { Symptomatic Status } \\
\mathbf{N}(\%)\end{array}$ & $\begin{array}{c}\text { P- } \\
\text { value }\end{array}$ \\
\hline \multirow{3}{*}{$\begin{array}{c}\text { Age } \\
\text { (years) }\end{array}$} & $18-25$ & 56 (71.79) & \multirow{3}{*}{0.802} \\
\hline & 26- 35 & $73(71.56)$ & \\
\hline & $\geq 36$ & $21(77.77)$ & \\
\hline \multirow{2}{*}{ Gender } & Male & $60(69.76)$ & \multirow{2}{*}{0.282} \\
\hline & Female & $90(74.38)$ & \\
\hline \multirow{4}{*}{$\begin{array}{c}\text { Co- } \\
\text { workers }\end{array}$} & One & $54(68.35)$ & \multirow{4}{*}{0.078} \\
\hline & Two & $42(82.35)$ & \\
\hline & Three & $16(61.53)$ & \\
\hline & $\begin{array}{l}\text { More than } \\
\text { three }\end{array}$ & $38(74.5)$ & \\
\hline \multirow{3}{*}{$\begin{array}{c}\text { Job } \\
\text { position }\end{array}$} & Dispenser & $124(74.25)$ & \multirow{3}{*}{0.085} \\
\hline & $\begin{array}{c}\text { Store } \\
\text { manager }\end{array}$ & $38(70.37)$ & \\
\hline & Store owner & $10(50)$ & \\
\hline
\end{tabular}

\section{Discussion}

Healthcare providers including pharmacists and pharmacy assistants are the first point of contact with patients in health care settings and therefore they are at an increased risk of contracting COVID-19 during an outbreak. Numerous pharmacists may have contracted COVID-19 while working in pharmacies. This study aims to roughly estimate the risk of COVID-19 exposure among pharmacists and pharmacy assistants working in pharmacies and determine the period in which most of them were infected with COVID-19. In addition, the study aims to identify the most common 
symptoms pharmacists have that may indicate COVID-19 infection. The majority of the respondents (72.46\%) reported having at least one or more flu-like symptoms while $52.17 \%$ among them reported that one of their relatives had at least one or more of the aforementioned symptoms.

In this survey, the period with the highest number of symptomatic pharmacists as well as those with symptoms suggestive of COVID-19 was between August to October 2020, and the peak was in August. These results may be explained by the $60 \%$ increase in confirmed cases of COVID-19 that was seen in Libya in August, which may have led to the pharmacists being infected. Correspondingly, among the tested respondents for COVID-19 (35), only eight respondents tested positive, and those respondents who tested positive had COVID-19 suggestive symptoms reported in the period between August and September. According to the WHO COVID-19 tracker (for Libya), the charts showed that there was a $60 \%$ increase in the confirmed cases (404) on August 7th and they continued to rise until they reached 1085 confirmed cases on September 7th. After that, the daily number of cases declined and started to rise again on October 6th reaching a peak on October 26th with 1639 confirmed cases. However, the number of confirmed cases reported since October 26 th have been relatively low. ${ }^{14}$

The most common symptoms reported by our respondents and their relatives include headache, tiredness, fever, and loss of smell and taste sensation. A study by Magnavita et al. $(2020)^{7}$ showed that the most common symptoms observed in infected health care workers (HCWs) were muscle pain $(52.4 \%)$ and tiredness $(47.6 \%)$ while, loss of smell and taste (>40\%) were very frequent in positive HCWs. However, fever and diarrhoea were reported less frequently by infected HCWs. The most frequently reported symptoms in a study on HCWs in Sweden by Rudberg et al. $(2020)^{8}$ were headache $(66 \%)$, tiredness $(65 \%)$, fever $(57 \%)$, cough $(52 \%)$, and loss of smell and taste (anosmia and ageusia) (>53\%).

Moreover, a study by Cabas et al. (2021) ${ }^{10}$ that assessed community pharmacists' exposure to COVID-19 found that $38.2 \%$ of the pharmacists developed at least one COVID-19 related symptom and the most common symptoms reported by the majority were headache (46.86\%), fever (31.88\%), tiredness (42.51\%), and loss of smell and taste sensation (28.9\%). Furthermore, Lai et al. (2020) ${ }^{18}$ investigated the most common COVID-19 symptoms among health care providers in a tertiary hospital in Wuhan, China. The results showed that the most common symptoms were fever (60.9\%) followed by myalgia or fatigue $(60.0 \%)$, cough $(56.4 \%)$, sore throat $(50.0 \%)$, and muscle ache $(45.5 \%)$. However, most health care workers with COVID-19 had a non-severe disease, with an asymptomatic carrier prevalence.
In this study, the majority of respondents reported that they had flu-like symptoms. These symptoms were considered as highly suggestive COVID-19 symptoms in the period that showed a rise in COVID-19 confirmed cases in Libya. This may indicate that community pharmacists and pharmacy assistants as a part of the primary health care providers have a high risk of exposure to COVID-19. According to reports of the Centers for Disease Control and Prevention (CDC) in the USA, 55\% of health care providers (patients) reported contact with a COVID-19 patient only in health care settings and the majority (92\%) of health care providers (patients) reported having at least one symptom among fever, cough, or shortness of breath. ${ }^{19}$ Besides, according to Shah et al. $(2020)^{20}, 17 \%$ of COVID-19 patients admitted to hospitals were mainly healthcare workers and their household members. The risk of contracting COVID-19 is two to three times more in the case of patients who are in contact with healthcare workers and their household members.

In the current study, $53.47 \%$ of the respondents reported that their symptoms lasted less than 7 days and very few reported that their symptoms lasted more than 15 days. A study that was conducted in Beijing, China shows that fever was present in $87.5 \%$ of patients, which persisted for 6 days. ${ }^{9}$ However, according to Sharma et al. (2020), fever in COVID-19 may have a prolonged duration (up to 14 days). ${ }^{21}$

The majority of respondents had no comorbidities, with a lower percentage of those who had one comorbidity or more. Respiratory diseases were the most common comorbidity that respondents had. On other hand, a small percentage of the respondents' relatives had no comorbidities, while, the percentage of relatives who had one comorbidity or more was higher. Diabetes and hypertension were among the most common comorbidities the relatives had and respiratory and cardiovascular diseases were seen less. The findings of Cabas et al. (2021) are roughly comparable with ours, as they observed that among pharmacists who answered the survey, the majority (81.3\%) reported having no comorbidities. ${ }^{10}$ This could be because most of the respondents were relatively young belonging to the age group of 25-35 years. However, the majority of respondents' relatives were seniors belonging to the age group above 50 years. Older adults have relatively higher risks and rates of comorbidities.

From our results, there was a significant association between the number of comorbidities in respondents' relatives and ICU admission. As those with diabetes, immunodeficiency, and respiratory diseases were more likely to be admitted to the ICU. In addition, the increased number of comorbidities was significantly associated with ICU admission. According to Sanyaolu et al. (2020) and Richardson et al. (2020), the admission rate in the ICU and the mortality increased as 
the patient's age increases, and the majority of COVID-19 deaths involved at least one comorbidity. ${ }^{9,22}$ Diabetic and hypertensive patients are more likely to develop a more severe course and progression of the disease and are linked to more hospitalisation and ICU admissions. ${ }^{9,22}$

Guan et al. (2020) found that the most common comorbidities associated with poorer prognosis are diabetes, hypertension, respiratory diseases, cardiac diseases, renal diseases and malignancies. ${ }^{23}$ They stated that as compared to non-severe cases, two or more comorbidities were more frequently found in severe cases. Sharma et al. (2020) found that diseases like uncontrolled hypertension, diabetes, immunodeficiency, and coronary heart disease are the major underlying comorbidities that complicate the course of COVID-19 by increasing the severity of illness, use of mechanical ventilation, and length of ICU stay, thus increase the mortality. ${ }^{21}$

Most of our respondents reported the use of wearing masks as personal protective devices in their workplaces. $57.07 \%$ used physical barriers, and $42.44 \%$ adopted social distancing (were maintaining a safe distance of $2 \mathrm{~m}$ from customers). Only a few cases were reported using no protective measures. $30.43 \%$ of pharmacists reported using at least two protective measures, and $25.6 \%$ used three protective measures. A study by Zaidi \& Hasan (2021) indicates that there are $42.7 \%$ of pharmacists who use at least two protective measures, $27.7 \%$ use three protective measures, most pharmacists (>85\%) adopted social distancing, and $72 \%$ were wearing protective masks (N95). ${ }^{24}$ According to Cabas et al. (2021), 98.3\% of pharmacists reported that they used two or more protective measures, $87.9 \%$ of them adopted physical barriers as a protective measure, and $68.8 \%$ of them adopted social distancing. ${ }^{10}$ Additionally, Hoti et al. (2020) revealed that the major protective measures used by pharmacists were gloves (97\%) and hand disinfectants (96.2\%), followed by surgical masks (81.1\%) and less frequently N95 masks (66.25\%). ${ }^{25}$ These results were different from that of our study.

\section{Limitations}

Our study has some limitations. Firstly, the sample size may be considered small. Small sample size could reduce the power of the study and increase the margin of error, and it can lead to cases of bias. Secondly, we used an online questionnaire, and it has its drawbacks, including misunderstanding of questions by the respondents, multiple responses by the same respondent and lack of credibility.

\section{Conclusion}

In this study, the results showed that the majority of respondents reported having flu-like symptoms in the period from August to October 2020. Moreover, the highest cumulative number of those with suggestive COVID-19 symptoms reported their symptoms in the same period. That may indicate that the community pharmacists and pharmacy assistants as a part of primary health care providers had a high risk of exposure to COVID-19 in the period that showed a rise in COVID-19 confirmed cases in Libya before the peak (October 26th, 2020). In addition, there was a significant association between the number of comorbidities in respondents' relatives and ICU admission.

\section{Funding Statement: None \\ Conflict of Interest: None}

\section{References}

1. Di Gennaro F, Pizzol D, Marotta C, Antunes M, Racalbuto V, Veronese N, Smith L. Coronavirus diseases (COVID-19) current status and future perspectives: a narrative review. Int J Environ Res Public Health. 2020;17(8):2690. [PubMed] [Google Scholar]

2. Lai CC, Shih TP, Ko WC, Tang HJ, Hsueh PR. Severe acute respiratory syndrome coronavirus 2 (SARSCoV-2) and coronavirus disease-2019 (COVID-19): The epidemic and the challenges. Int J Antimicrob Agents. 2020;55(3):105924.[PubMed] [Google Scholar]

3. Syed A. Coronavirus: a mini-review. Int J Curr Res Med Sci. 2020;6(1):8-10. [Google Scholar]

4. Wang Z, Deng H, Ou C, Liang J, Wang Y, Jiang M, Li S. Clinical symptoms, comorbidities and complications in severe and non-severe patients with COVID-19: A systematic review and meta-analysis without cases duplication. Medicine. 2020;99(48):e23327. [PubMed] [Google Scholar]

5. Patel A, Jernigan DB; 2019-nCoV CDC Response Team. Initial Public Health Response and Interim Clinical Guidance for the 2019 Novel Coronavirus Outbreak United States, December 31, 2019-February 4, 2020. MMWR Morb Mortal Wkly Rep. 2020 Feb 7;69(5):1406. [PubMed] [Google Scholar]

6. Rogge MM, Gautam B. COVID-19: Epidemiology and clinical practice implications. Nurse Pract. 2020;45(12):26. [PubMed] [Google Scholar]

7. Magnavita N, Tripepi G, Di Prinzio RR. Symptoms in health care workers during the COVID-19 epidemic. A cross-sectional survey. Int J Environ Res Public Health. 2020;17(14):5218. [PubMed] [Google Scholar]

8. Rudberg AS, Havervall S, Månberg A, Falk AJ, Aguilera K, Ng H, Gabrielsson L, Salomonsson AC, Hanke L, Murrell B, Mclnerney G, Olofsson J, Andersson E, Hellstrom C, Bayati S, Bergstrom S, Pin E, Sjoberg $R$, Tegel $H$, Hedhammar $M$, Phillipson $M$, Nilsson $P$, Hober S, Thålin C. SARS-CoV-2 exposure, symptoms and seroprevalence in healthcare workers in Sweden. Nat Commun. 2020;11(1):1-8 [PubMed] [Google Scholar] 
9. Sanyaolu A, Okorie C, Marinkovic A, Patidar R, Younis K, Desai P, Hosein Z, Padda I, Mangat J, Altaf M. Comorbidity and its impact on patients with COVID-19. SN Compr Clin Med. 2020;2:1-8. [PubMed] [Google Scholar]

10. Cabas P, Di Bella S, Giuffrè M, Rizzo M, Trombetta C, Luzzati R, Antonello RM, Parenzan K, Liguori G. Community pharmacists' exposure to COVID-19. Res Social Adm Pharm. 2021;17(1):1882-7. [PubMed] [Google Scholar]

11. Dzingirai B, Matyanga CMJ, Mudzviti T, Siyawamwaya $M$, Tagwireyi D. Risks to the community pharmacists and pharmacy personnel during COVID-19 pandemic: perspectives from a low-income country. J Pharm Policy Prac. 2020;13(1):1-6. [Google Scholar]

12. Bredan A, Bakoush O. COVID-19 epidemic in Libya. Libyan J Med. 2021;16(1):1871798. [PubMed] [Google Scholar]

13. Elmehdawi RR, Jaweesh RS, Elbadri AA, Zue MH, Elsoor $F F$, Elhaddad AB, Belkasem FS. Clinical, biochemical, and radiological characteristics of the first cluster of Covid-19 cases in Benghazi, Libya: Case series. Libyan J Med Sci. 2020;4(3):143. [Google Scholar]

14. World Health Organisation [Internet]. Covid-19 dashboard; 2021 [cited 2021 Jul 7], Available from: https://covid19.who.int/region/emro/country/ly

15. Ng K, Poon BH, Kiat Puar TH, Shan Quah JL, Loh WJ, Wong YJ, Tan TY, Raghuram J. COVID-19 and the risk to health care workers: a case report. Ann Intern Med. 2020;172(11):766-7. [PubMed] [Google Scholar]

16. Hedima EW, Adeyemi MS, Ikunaiye NY. Community Pharmacists: On the frontline of health service against COVID-19 in LMICs. Res Social Adm Pharm. 2021;17(1):1964-6. [PubMed] [Google Scholar]

17. Bandyopadhyay $S$, Baticulon RE, Kadhum M, Alser M, Ojuka DK, Badereddin Y, Kamath A, Parepalli SA, Brown G, Iharchane S, Gandino S, Markovic-Obiago Z, Scott S, Manirambona E, Machhada A, Aggarwal A, Benazaize L, Ibrahim M, Kim D, Tol I, Taylor EH, Knighton A, Bbaale D, Jasim D, Alghoul H, Reddy H, Abuelgasim $H$, Saini K, Sigler A, Abuelgasim L, Moran-Romero M, Kumarendran M, Jamie NA, Ali O, Sudarshan R, Dean R, Kisyova R, Kelzang S, Roche S, Ahsan T, Mohamed Y, Dube AM, Gwini GP, Gwokyala R, Brown R, Papon MR, Li Z, Ruzats SS, Charuvila S, Peter N, Khalidy K, Moyo N, Alser O, Solano A, Robles-Perez E, Tariq A, Gaddah M, Kolovos S, Muchemwa FC, Saleh A, Gosman A, Pinedo-Villanueva R, Jani A, Khundkar R. Infection and mortality of healthcare workers worldwide from COVID-19: a systematic review. BMJ Glob Health. 2020;5(12):e003097. [PubMed] [Google Scholar]

18. Lai X, Wang M, Qin C, Tan L, Ran L, Chen D, Zhang H, Shang K, Xia C, Wang S, Xu S, Wang W. Coronavirus disease 2019 (COVID-2019) infection among health care workers and implications for prevention measures in a tertiary hospital in Wuhan, China. JAMA Netw Open. 2020;3(5):e209666. [PubMed] [Google Scholar]

19. CDC COVID-19 Response Team. Characteristics of health care personnel with COVID-19 - United States, February 12-April 9, 2020. MMWR Morb Mortal Wkly Rep. 2020;69(15):477. [PubMed] [Google Scholar]

20. Shah AS, Wood R, Gribben C, Caldwell D, Bishop J, Weir A, Kennedy S, Reid M, Smith-Palmer A, Goldberg D, McMenamin J, Fischbacher C, Robertson C, Hutchinson $\mathrm{S}$, McKeigue P, Colhoun H, McAllister DA. Risk of hospital admission with coronavirus disease 2019 in healthcare workers and their households: nationwide linkage cohort study. BMJ. 2020;371:m3582. [PubMed] [Google Scholar]

21. Sharma R, Agarwal M, Gupta M, Somendra S, Saxena SK. Clinical Characteristics and Differential Clinical Diagnosis of Novel Coronavirus Disease 2019 (COVID-19). In: Saxena SK, editor. Coronavirus Disease 2019 (COVID-19): Epidemiology, Pathogenesis, Diagnosis, and Therapeutics. Singapore: Springer; 2020;55-70. [Google Scholar]

22. Richardson S, Hirsch JS, Narasimhan M, Crawford JM, McGinn T, Davidson KW; the Northwell COVID-19 Research Consortium; Barnaby DP, Becker LB, Chelico JD, Cohen SL, Cookingham J, Coppa K, Diefenbach MA, Dominello AJ, Duer-Hefele J, Falzon L, Gitlin J, Hajizadeh N, Harvin TG, Hirschwerk DA, Kim EJ, Kozel ZM, Marrast LM, Mogavero JN, Osorio GA, Qiu M, Zanos TP. Presenting characteristics, comorbidities, and outcomes among 5700 patients hospitalized with COVID-19 in the New York City area. JAMA. 2020;323(20):2052-9. [PubMed] [Google Scholar]

23. Guan WJ, Liang WH, Zhao Y, Liang HR, Chen ZS, Li YM, Liu XQ, Chen RC, Tang CL, Wang T, Ou CQ, Li L, Chen PY, Sang L, Wang W, Li JF, Li CC, Ou LM, Cheng B, Xiong S, Ni ZY, Xiang J, Hu Y, Liu L, Shan H, Lei CL, Peng YX, Wei L, Liu Y, Hu YH, Peng P, Wang JM, Liu JY, Chen Z, Li G, Zheng ZJ, Qiu SQ, Luo J, Ye CJ, Zhu SY, Cheng LL, Ye F, Li SY, Zheng JP, Zhang NF, Zhong NS, He JX; China Medical Treatment Expert Group for COVID-19. Comorbidity and its impact on 1590 patients with COVID-19 in China: a nationwide analysis. Eur Respir J. 2020;55(5):2000547. [PubMed] [Google Scholar]

24. Zaidi ST, Hasan SS. Personal protective practices and pharmacy services delivery by community pharmacists 
during COVID-19 pandemic: results from a national survey. Res Social Adm Pharm. 2021;17(1):1832-7. [PubMed] [Google Scholar]

25. Hoti K, Jakupi A, Hetemi D, Raka D, Hughes J, Desselle $\mathrm{S}$. Provision of community pharmacy services during COVID-19 pandemic: a cross sectional study of community pharmacists' experiences with preventative measures and sources of information. Int J Clin Pharm. 2020;42(4):1197-206. [PubMed] [Google Scholar] 